\title{
Implicações do cumprimento do Código Florestal vigente na redução de áreas agrícolas: um estudo de caso da produção canavieira no Estado de São Paulo
}

\author{
Pedro Henrique Santin Brancalion ${ }^{1,3}$ \& Ricardo Ribeiro Rodrigues ${ }^{2}$ \\ ${ }^{1}$ Departamento de Ciências Florestais, Escola Superior de Agricultura "Luiz de Queiroz", \\ Universidade de São Paulo - USP, Av. Pádua Dias 11, CEP 13418-900, Piracicaba, SP, Brasil \\ ${ }^{2}$ Departamento de Ciências Biológicas, Escola Superior de Agricultura "Luiz de Queiroz", \\ Universidade de São Paulo - USP, Av. Pádua Dias 11, CEP 13418-900, Piracicaba, SP, Brasil \\ ${ }^{3}$ Autor para correspondência: Pedro Henrique Santin Brancalion, e-mail: pedrohsb@yahoo.com.br
}

\begin{abstract}
BRANCALION, P.H.S. \& RODRIGUES, R.R. Agricultural land reduction due to the compliance with the current Forest Code: a study case of sugarcane production in the State of São Paulo. Biota Neotrop. 10(4): http://www.biotaneotropica.org.br/v10n4/en/abstract?article+bn01010042010.
\end{abstract}

\begin{abstract}
One of the major reasons of the proposed changes of the Brazilian Forest Code is that its compliance would supposedly harm several agricultural sectors, although this reason has been weakly supported by data. The goal of this work was to evaluate the implication of the compliance with the Forest Code for reducing areas of sugarcane production in the State of São Paulo, aiming to estimate the upper limit of potential losses that the application of the Forest Code could bring to the economic viability of important sectors of Brazilian agricultural production. We analyzed 23 projects of environmental planning carried out in 1,961 landholdings of sugarcane mills from São Paulo State, which totalized 533,097 ha $(9.7 \%$ of the cultivated area with sugarcane in the state). In these projects, we carried out an environmental zoning of Permanent Protected Areas (PPA), lands of agricultural production, and potential lands to constitute Legal Reserves. The results indicated that, on average, $10.4 \%$ of the total area of each farm was classified as PPA, and that only $21.2 \%$ of PPA area (2.2\% of the total area) were occupied by some kind of agricultural production. Sugarcane occupied, in average, $12.1 \%$ of the areas classified as PPA (1.2\% of the total area). Overall, $76.5 \%$ of the total area of projects was occupied by sugarcane fields and the sum of potential areas for compliance with the Legal Reserve, which were constituted by forest remnants (5.0\% of total area), abandoned lands ( $2.3 \%$ of total area), and lands with other uses (6.3\% of total area), would result in $13.6 \%$ of the total area and consequently generate a deficit of $6.4 \%$ of lands for the full compliance with the Legal Reserve (20\%). This deficit could even be compensated, by law, outside the landholding register in landscapes with lower agriculture suitability. Therefore, the diagnostics presented in this work for the sugarcane sector in the State of São Paulo indicates that compliance with the current Forest Code would not reduce agricultural production, which highlight that part of the arguments that are favorable for changes in the Forest Code need to be revisited in the light of concrete data and in a less speculative way.
\end{abstract}

Keywords: environmental policy, environmental planning, land use, riparian areas, forest restoration.

BRANCALION, P.H.S. \& RODRIGUES, R.R. Implicações do cumprimento do Código Florestal vigente na redução de áreas agrícolas: um estudo de caso da produção canavieira no Estado de São Paulo. Biota Neotrop. 10(4): http://www.biotaneotropica.org.br/v10n4/pt/abstract?article+bn01010042010.

Resumo: Uma das principais justificativas da proposta de mudanças do Código Florestal brasileiro (CF) é a de que seu cumprimento supostamente inviabilizaria vários setores da agropecuária, apesar dessa justificativa ser fracamente sustentada em dados. O objetivo desse trabalho foi avaliar as implicações do cumprimento do CF para a redução de áreas de produção canavieira no Estado de São Paulo, visando estimar qual seria o limite superior de potenciais prejuízos que a aplicação do CF poderia trazer à viabilidade econômica de um dos mais importantes, e também impactantes ambientalmente, segmentos da produção agropecuária brasileira. Foram analisados 23 projetos de adequação ambiental conduzidos em 1.961 propriedades rurais de usinas sucroalcooleira do Estado de São Paulo, os quais totalizaram 533.097 ha (9,7\% da área cultivada com cana-de-açúcar em São Paulo). Nesses projetos, realizaram-se um diagnóstico ambiental de Áreas de Preservação Permanente (APP), áreas de produção agrícola e de áreas potenciais para constituir a Reserva Legal. Os resultados indicaram que 10,4\% da área total das propriedades rurais constituiriam APPs e que apenas $21,2 \%$ da área de APP (2,2\% da área total) era utilizada por algum tipo de atividade agrícola, sendo que cana-de-açúcar ocupava apenas 12,1\% da área enquadrada como APP pelo atual Código (1,2\% da área total). Em média, 76,5\% da área total dos projetos estavam ocupadas por cana-de-açúcar e a soma das áreas potencias para a averbação da Reserva Legal, constituídas de remanescentes florestais $(5,0 \%$ da área total), áreas abandonadas (2,3\% da área total) e de áreas com outros usos (6,3\% da área total), resultaria em 13,6\% da área total, gerando um déficit médio de 6,4\% de áreas para o total cumprimento da Reserva Legal (20\%). Esse déficit poderia, por lei, inclusive ser compensado fora da matrícula, em paisagens de menor aptidão agrícola. Assim, o diagnóstico apresentado nesse trabalho para o setor canavieiro no Estado de São Paulo aponta que o CF vigente poderia ser cumprido sem inviabilizar a produção agrícola, ressaltando que parte dos argumentos favoráveis às alterações no $\mathrm{CF}$ precisa ser revista à luz de dados concretos e de forma menos especulativa.

Palavras-chave: política ambiental, planejamento ambiental, uso do solo, áreas ripárias, restauração florestal. 


\section{Introdução}

O Código Florestal Brasileiro (CF), estabelecido por meio da Lei 10.711 de 1965 e modificado posteriormente por outros instrumentos legais, tem como principal prerrogativa a conciliação da preservação ambiental e do manejo sustentável dos recursos naturais com o uso e ocupação do solo pelo homem. Dentre o conjunto de medidas protecionistas contidas no Código Florestal, destacam-se as Áreas de Preservação Permanente (APPs) e as de Reserva Legal (RL), as quais estabelecem normas para que as atividades de produção agropecuária possam ser conduzidas resguardando-se a conservação da biodiversidade e a geração de serviços ambientais.

Ultimamente, o cumprimento do $\mathrm{CF}$ por empresas agrícolas brasileiras exportadoras de matérias primas, principalmente açúcar, celulose, grãos e carne, tem sido um dos requisitos para que se obtenha a certificação ambiental da produção, a qual tem sido cada vez mais exigida para o acesso a mercados externos (Rodrigues et al. 2010). Por outro lado, programas governamentais visando à regularização ambiental de pequenas propriedades rurais também têm sido conduzidos com base no CF (Wuethrich 2007, Rodrigues et al. 2010).

Contudo, o setor agrícola ainda é reticente em relação ao $\mathrm{CF}$, alegando que seu cumprimento poderia inviabilizar a produção e reduzir a competitividade do agronegócio brasileiro no mercado externo, uma vez que os países competidores não possuem leis ambientais restritivas como as do Brasil. Tal argumento é a principal justificativa para a tentativa de flexibilização do $\mathrm{CF}$, apesar das implicações ambientais negativas já insistentemente comprovadas (Metzger et al. 2010, Michalski et al. 2010). No entanto, dado o avanço da atividade de produção agrícola e do conhecimento científico nesses quase cinquenta anos de sua vigência, certamente o $\mathrm{CF}$ atual precisa ser revisto em vários de seus conceitos e aplicações, inclusive para incentivar a produção agrícola com sustentabilidade ambiental, mas não com a bandeira de que o CF vigente está inviabilizando a disponibilização de áreas para a expansão da agropecuária no país. Justamente para que o debate em torno desse tema de atualização do $\mathrm{CF}$ vigente seja conduzido de forma mais objetiva e suportada no conhecimento científico, é fundamental que se responda uma pergunta chave: quais as reais implicações do cumprimento do CF vigente para o agronegócio brasileiro? Apesar de ser uma pergunta complexa e de difícil generalização espacial, cuja resposta depende do tipo de cultivo e da região geográfica considerada, é possível partir-se de um estudo de caso que considere um sistema de produção altamente intensificado e de grande tecnologia, com potencial de grande impacto ambiental, para o qual o cumprimento do CF certamente representaria forte limitação do uso do solo, tal como a produção de cana-de-açúcar no Estado de São Paulo.

O Estado de São Paulo é o maior produtor brasileiro de canade-açúcar, com $58 \%$ da produção nacional (São Paulo 2008). Os 5,5 milhões de ha cultivados com essa cultura (32,2\% da área agrícola do estado) estão instalados em áreas de antigo histórico de uso e ocupação antrópica, onde a conversão de florestas naturais em cultivos agrícolas ocorreu principalmente entre as metades do século XIX e XX com o ciclo do café, antes mesmo da existência de medidas protecionistas como o CF (Dean 1996). Consequentemente, parte expressiva das áreas de produção canavieira se estabeleceu em um modelo prévio de uso e ocupação do solo que desrespeitava o CF. Hoje, há menos de $9 \%$ de cobertura florestal nativa no interior do Estado de São Paulo (SIFESP 2010), e a maioria das áreas de alta aptidão agrícola está ocupada por cultivos de cana-de-açúcar. Trata-se, evidentemente, de um dos modelos de agricultura para o qual o cumprimento do $\mathrm{CF}$ seria mais restritivo, dado o antigo e intenso uso do solo.
Assim, o objetivo desse trabalho é avaliar as implicações do cumprimento do CF para a redução de áreas de produção canavieira no Estado de São Paulo, visando estimar qual seria o limite superior de potenciais prejuízos que a aplicação do CF vigente poderia trazer à viabilidade econômica de um dos mais importantes segmentos da produção agropecuária brasileira.

\section{Material e Métodos}

Os dados utilizados foram obtidos por meio do Programa de Adequação Ambiental conduzido pelo Laboratório de Ecologia e Restauração Florestal, da Escola Superior de Agricultura "Luiz de Queiroz", Universidade de São Paulo (www.lerf.esalq.usp.br). Para o presente trabalho, foram utilizados dados de 23 projetos de adequação ambiental de usinas sucroalcooleiras do Estado de São Paulo, os quais foram obtidos em 1.961 propriedades rurais. A área total desses projetos (533.097 ha) equivale a 9,7\% da área cultivada com cana-deaçúcar no Estado de São Paulo, o que ressalta a representatividade da amostra. Cabe ressaltar que os resultados do diagnóstico conduzido pelo Programa de Adequação Ambiental dessas usinas expressam uma condição de produção convencional e sem um amplo planejamento ambiental para se atender ao $\mathrm{CF}$, uma vez que tal planejamento foi justamente conduzido posteriormente a partir do diagnóstico inicial dessas áreas, como parte do programa de adequação.

Foi realizada a quantificação das seguintes situações em cada Programa de Adequação Ambiental: i) APPs; ii) uso das APPs por atividades de produção e, de forma particular, para o cultivo de cana-de-açúcar, iii) remanescentes naturais de vegetação nativa fora de APPs; iv) áreas abandonadas fora de APP; v) áreas de produção de cana-de-açúcar fora de APPs (incluindo os plantios, carreadores e canais de vinhaça); e vi) outros usos não canavieiros (tal como pecuária, reflorestamentos comerciais, cultivos perenes, etc.). Um detalhamento maior do diagnóstico das APPs para fins de restauração florestal pode ser verificado em Rodrigues et al. (2010). Essas informações foram levantadas por meio da seguinte sequência de atividades: i) aquisição de fotografias aéreas recentes (1: 25.000 - 1: 30.000) para as áreas do projeto; ii) fotointerpretação para a delimitação das APPs e determinação de sua ocupação atual; iii) fotointerpretação para a delimitação dos fragmentos florestais e demais situações de campo fora das APPs; iv) checagem de campo dos mapas gerados a partir da fotointerpretação; v) correção dos mapas com base na checagem de campo; e vi) construção do mapa final com um Sistema de Informação Geográfica.

\section{Resultados}

Os Programas de Adequação Ambiental descritos nesse trabalho apresentaram, em média, 10,4\% da área total das propriedades rurais ocupada por APPs (Tabela 1). Apenas 2,2\% da área total $(21,2 \%$ da APP) era utilizada para algum tipo de atividade produtiva (canade-açúcar, pecuária, reflorestamentos comerciais, pomares, etc.), e $1,2 \%$ da área total $(12,1 \%$ da APP) estava ocupada com cana-deaçúcar (Tabela 1). O diagnóstico das áreas fora de APPs evidenciou que, em média, $76,5 \%$ da área total dos projetos estava ocupada por cultivos de cana-de-açúcar (Tabela 1). A soma das áreas potencias para a averbação da RL, constituídas de remanescentes florestais (em média, 5,0\% da área total), áreas abandonadas (em média, 2,3\% da área total) e de áreas com outros usos (em média, 6,3\% da área total), resultaria em 13,6\% da área total, gerando um déficit médio de 6,4\% de áreas para a averbação da RL.

\section{Discussão}

Um dos principais pontos polêmicos defendidos pela proposta de substitutivo do CF é a redução da faixa de APPs de 30 para $15 \mathrm{~m}$ 
Redução de áreas de produção canavieiras pela aplicação do Código Florestal

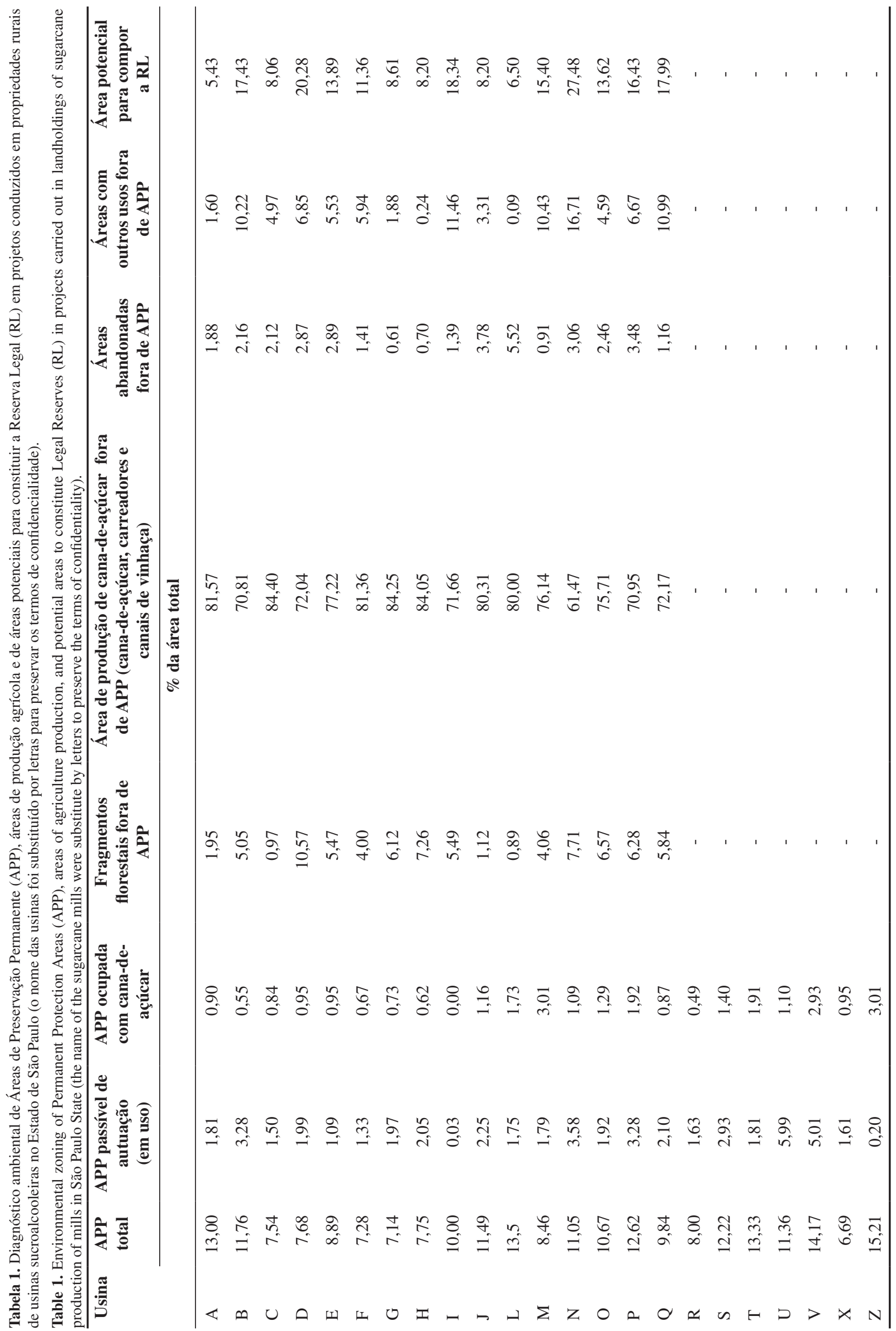


para cursos d'água com largura inferior a $5 \mathrm{~m}$. Considerando-se que a maior parte da malha hidrográfica é constituída justamente por cursos d'água estreitos, essa medida resultaria em uma redução expressiva das áreas protegidas como APPs. Propõe-se ainda que a faixa de APPs seja medida, para qualquer curso d'água natural, a partir de seu leito menor, ao invés de se adotar o leito maior como referência, conforme proposto no $\mathrm{CF}$ vigente, o que também resultaria em redução da proteção de APPs ripárias ou ribeirinhas. A justificativa para ambas as mudanças é que a viabilidade econômica das atividades de produção agropecuária seria comprometida pela quantidade maior de áreas destinadas à proteção de áreas ripárias.

Contudo, ao se analisar a situação da produção canavieira no Estado de São Paulo, essa justificativa não é validada em dados científicos. Considerando-se os limites estabelecidos pelo $\mathrm{CF}$ vigente, apenas $1,26 \%$ da área total das propriedades rurais $(12,1 \%$ da APP) eram utilizadas para a produção de cana-de-açúcar, o que corresponde a apenas $1,6 \%$ da área ocupada por essa cultura. Contudo, houve variação expressiva nos resultados obtidos para cada um dos 23 projetos, evidenciando que o cumprimento do CF traria consequências amplamente variáveis na redução da área disponível para a produção canavieira, em função das condições ambientais locais e da política ambiental da empresa considerada.

Com relação à composição da RL, seria necessário, em média, que $6,4 \%$ da área total utilizada para a produção de cana-de-açúcar fossem convertidas em florestas. Contudo, houve também expressiva variação entre os projetos nos valores da potencial perda de áreas de produção canavieira para compor a RL. Do grupo de projetos analisado, duas usinas conseguiriam compor a RL sem alterar a área de produção de cana-de-açúcar (D e N - Tabela 1) e três usinas precisariam ceder apenas cerca de $3 \%$ da área $(\mathrm{B}, \mathrm{I}$ e $\mathrm{Q})$, ao passo que seis usinas (A, C, G, H, J e L) precisariam de mais de $10 \%$ de área cultivada a mais para regularizar a RL. Dessa forma, não seria necessário hoje eliminar a necessidade de RL para propriedades rurais com menos de quatro módulos rurais, ou descontar esses quatro módulos sem RL de propriedades maiores, para que as atuais unidades de produção canavieira possam se regularizar ambientalmente sem prejuízos de produção, principalmente considerando a possibilidade da legislação vigente de compensação desse déficit de RL fora da matrícula na paisagem regional, em áreas de menor aptidão agrícola, não restringindo assim as áreas para produção canavieira.

Há de se considerar também que a regularização ambiental e legal das unidades de produção canavieira pode possibilitar a certificação ambiental e, consequentemente a quebra de barreiras e uma possível abertura de mercados internacionais para o açúcar e álcool, compensando financeiramente a potencial perda de áreas de produção, inclusive pela sua pequena expressão. Além disso, os ganhos cada vez maiores de produtividade no setor apontam que o mesmo nível de produção atual poderá ser obtido em áreas cada vez menores, favorecendo com que setores das propriedades agrícolas possam ser destinados a modalidades de uso do solo menos impactantes à biodiversidade e à geração de serviços ambientais, tal como preconizado no CF vigente e apontado pela pesquisa (Metzger 2010).

Assim, o diagnóstico apresentado nesse trabalho para o setor canavieiro no Estado de São Paulo aponta que o CF vigente poderia ser cumprido sem inviabilizar a produção, ressaltando que as alterações que se fazem necessárias do $\mathrm{CF}$ vigente precisam ser feitas de forma menos especulativa e à luz de conhecimento científico já disponibilizado, inclusive gerando demandas direcionadas de pesquisas futuras para o aprimoramento da legislação ambiental brasileira, viabilizando o aumento da produção agropecuária, em termos espaciais e de produtividade, mas com sustentabilidade ambiental.

\section{Referências Bibliográficas}

DEAN, W. 1996. A ferro e fogo: a história e a devastação da Mata Atlântica brasileira. Companhia das Letras, São Paulo.

METZGER, J.P. 2010. O código florestal tem base científica? Natureza \& Conservação (8):1-5.

METZGER, J.P., LEWINSHON, T., JOLY, C.A., VERDADE, L.M., MARTINELLI, L.A., RODRIGUES, R.R. 2010. Brazilian law: full speed in reverse? Science (329): 276.

MICHALSKI, F. NORRIS, D., PERES, C.A. 2010. No return from biodiversity loss. Science (329): 1282.

RODRIGUES, R.R., GANDOLFI, S., NAVE, A.G., BARRETO, T.E., VIDAL, C.Y. \& BRANCALION, P.H.S. 2010. Large-scale ecological restoration of high-diversity tropical forests in SE Brazil. For. Ecol. Manag. (no prelo).

SÃO PAULO (Estado). 2008. Secretaria de Agricultura e Abastecimento. Coordenadoria de Assistência Técnica Integral. Instituto de Economia Agrícola. Levantamento censitário de unidades de produção agrícola do Estado de São Paulo - LUPA 2007/2008. SAA/CATI/IEA, São Paulo, 2008. http://www.cati.sp.gov.br/projetolupa (último acesso em 02/06/2010).

SISTEMA DE INFORMAÇÕES FLORESTAIS DO ESTADO DE SÃO PAULO - SIFESP. 2010. www.iflorestal.sp.gov.br/sifesp (último acesso em 02/06/2010).

WUETHRICH, B. 2007. Reconstructing Brazil's Atlantic Rainforest. Science (315): 1070 . 